\title{
Traditional Foods in Europe: Perceptions \& Prospects in the New Business Era
}

\author{
Dimitris Skalkos* \\ Department of Chemistry, Laboratory of Food chemistry, Ioannina 45110, Greece
}

ISSN: 2637-7659

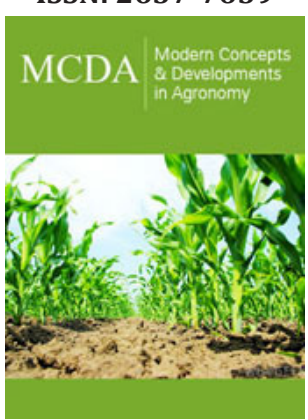

*Corresponding author: Dimitris Skalkos, Department of Chemistry, Laboratory of Food chemistry, Ioannina 45110, Greece

Submission: 眥 February 16, 2021

Published: 悳March 04, 2021

Volume 8 - Issue 2

How to cite this article: Dimitris Skalkos. Traditional Foods in Europe: Perceptions \& Prospects in the New Business Era. Mod Concep Dev Agrono. 8(2). MCDA. 000681. 2021. DOI: 10.31031/MCDA.2021.08.000681

Copyright@ Dimitris Skalkos. This article is distributed under the terms of the Creative Commons Attribution 4.0 International License, which permits unrestricted use and redistribution provided that the original author and source are credited.

\begin{abstract}
Traditional Foods (T.F.) in Europe constitute a minor part of the food chain, with the production and consumption remaining within certain territories. They are healthy, unique innovative products, attractive to the end consumer. COVID-19 will have an impact on the whole process from the field to the consumer concerning issues such as food safety, food security bioactive ingredients, production, processing, distribution. The current article explores the potentials of T.F. in the economic era after the pandemic crisis. T.F. have the opportunity to grow and expand beyond their local areas in Europe, becoming major part of the food chain for the benefit of regional producers and communities.
\end{abstract}

Keywords: Pandemic; COVID-19; Traditional foods; Food chains; Agriculture

\section{The European Food \& Drink Industry}

The European (EU-28) food and drink industry with an annual turnover of $€ 1,1$ trillion and $€ 230$ billion in value added in 2018, is the largest manufacturing industry in the EU [1]. In half of the EU's 28 Member States, the food and drink industry are the biggest employer within manufacturing employing 4,57 million people. In 2017, extra-EU exports reached $€ 110$ billion, with a trade surplus of $€ 35$ billion. The household expenditures, the second largest in EU, is in food and drink products reaching $13,8 \%$. The industry includes 294,000 Food and Drink companies operating in the EU-28, with 99,1\% of them SMEs, employing 4.57 million people. The European food companies are mostly micro companies by $80 \%$, employing nine people or less. SMEs are limited in their means allocated to market research and to research and development [2].

Europe cannot be regarded as a homogenous food culture. Noticeable differences exist not only at a national level but also at a more regional/local level in terms of food preferences, habits, food related behavior, and attitudes [3]. The existence of cultural variations in food choices throughout Europe has been demonstrated at different levels: the composition of protein diets [4], importance of food risk communication strategies [5], attitudes to food, nutrition and health [6] or food behavior [3]. This variability is even greater when dealing with Traditional Food Products (TFP) and traditional cuisine that are based mainly on the natural resources available in the area.

\section{Traditional Foods (TF) in Europe}

Southern European countries have a more traditional food character due to a greater market share of small companies and a better climate, which supports a more widespread availability of traditional food products [7]. The study of traditional foods provides an important insight into dietary patterns and how they have evolved over time. The fact that inhabitants had to adapt to different or adverse climatic conditions determined their dietary patterns, since people developed specific methods of cultivation, processing as well as preservation in order to ensure their self-sufficiency. In this way, dietary patterns have become an integral part of society's collective identity [8]. Traditional foods reflect cultural heritage, history, customs, way of life and even religion, representing key elements of dietary patterns in different countries and thus they are important for accurate calculation of dietary intake of population [9]. They have played a historically important role in traditions of different 
cultures and regions contributing to their sense of identity and pride [10]. The European Commission gave the following definition of "traditional" related to foods in 2006: "Traditional means proven usage in the community market for a time period showing transmission between generations; this time period should be the one generally ascribed as one human generation, at least 25 years" [11]. Apart from the commercial interests, the definition of the term "traditional" is an important issue addressed through the European Food Information Resource (FIR) FP6 Network of excellence [12]. This is an elaborative definition, which includes statements about traditional ingredients, traditional composition, and traditional type of production and/or processing [9]. In Europe, the only formal definition found for traditional food products comes from the Italian Ministry of Agriculture, that defines TFP as "Agrifood products whose methods of processing, storage and ripening are consolidated with time according to uniform and constant local use" [13]. Although these definitions try to capture the different dimensions of the concept of traditional food products, there is still one perspective that is still missing, namely a definition of this concept seen from the consumer's point of view.

The European Union in order to promote and protect names and quality of TFP defined three schemes of geographical indications and traditional specialties. As early as 1992 [14], the European Union laid down specific rules defining the status under which products are designated as Protected Designation of Origin (PDO), Protected Geographical Indication (PGI) and Traditionally Specific Guaranteed (TSG). This encourages the production of unique foods based on their soil, synthetic and sensory characteristics, as well as their preparation methods. This type of food enjoys a higher value, both in the domestic and international market. The above regulations in 2006 were amended to 510/06 and 509/06, respectively shortly after the Euro FIR London Congress $[15,16]$.

\section{The Traditional Products in the Post COVID-19 Era}

As traditional food products are highly valued for their authenticity, their main purpose is to maintain a strong link between customers and traditions and the area of origin [17]. Mainly produced by small industries/producers who use old recipes inherited from their ancestors, must deal with large companies that make traditional products industrially, without full compliance with natural ingredients and traditional recipes [18].

Traditional foods have good perspectives to grow in the future, if at least they would succeed in accomplishing challenges. One of the principal challenges identified is innovation, which can roughly be defined as improvements in the ways industries produce and commercialize things [19]. People increasing display a preference for natural entities which have been produced without human intervention in number of domains, especially food, such as TFP [20]. This preference may be associated with the fact that consumers are increasingly averse to risks induced by food innovation resulting from human intervention [21].

In the new economic era, following the end of the pandemic, the rebirth of borders and limitations to the movement of people, as well as the consequent sharp slowdown in foreign tourism, will favor ethnocentrism (with the preference given to national foods and traditional foods too). Production chains, which have been lengthened as result of globalization, will shorten again. On the other hand, traditional foods will be negatively affected by the lack of foreign tourism. Because of the additional attention to health care issues, the demand for products that threaten the future of the planet will be reduced, which itself would be a benefit to the consumption of traditional foods [22]. In addition, the crisis unfolded by COVID 19 will provide the impetus to change industrial agriculture for a transition towards agroecologically based food systems, including those of traditional foods [23]. The concept of "foodscapes", which unite local culture, creativity and food will become relevant in highlighting the importance linkages between novelty, authenticity and locality in food experience provided by traditional foods [24]. There will be a clear shift from location of production for T.F. to a wide and more holistic place and destination production process. Overall, the importance of the role and the meaning of T.F. to the regions of Europe are expected to be emphasized among regional stakeholders (farmers, distributors, residents, local politicians etc.) and reinforced by innovative marketing-related actions. However, these views need to be adapted, and promoted by the local, regional, national authorities on a pan-European scale in order to achieve the prospective and the growth of T.F. in the new economic era.

\section{References}

1. (2018) Data \& Trends of the European food and drink industry.

2. Gellynck X, Banterle A, Kuhne B, Carraresi I, Stranieri S (2012) Market orientation and marketing management of traditional food producers in the EU. British Food Journal 114(4): 481- 499.

3. Askegaard S, Madsen TK (1998) The local and the global: exploring traits of homogeneity and heterogeneity in European food cultures. International Business Review 7(6): 549-568.

4. Boer J, Helms M, Aiking H (2006) Protein consumption and sustainability: diet diversity in EU-15. Ecological Economics 59(3): 267-274.

5. Van Dijk H, Houghton J, van Kleef E, van der Lans I, Rowe G, et al. (2008) Consumer responses to communication about food risk management. Appetite 50(2-3): 340-352.

6. Lappalainen R, Kearney I, Gibney M, (1998) A pan EU survey of consumer attitudes to food. Nutrition and health: an overview. Food Quality and Preference 9(6): 467-478.

7. Jordana J (2000) Traditional foods: challenges facing the European food industry. Food Research International 33(3-4): 147-152.

8. Behar M (1976) European diets vs traditional foods. Food Policy 1(5): 432-435.

9. Trichopoulou A, Soukara S, Vasilopoulou E, (2007) Traditional foods: a science and society perspective, Trends in Food Science \& Technology 18(8): 420-427.

10. Almi VL (2012) Consumer acceptance of innovations in traditional food. Attitudes expectations and perception, Doctoral thesis, Norwegian University of Life Sciences, Norway.

11. EU, Council Regulation (EC) (2006) No 509/2006 of 20 March 2006 on agricultural products and foodstuffs as traditional specialties guaranteed. Official Journal of the European Union L 93/1.

12. Euro FIR (2007) FOD-CT-2005-5139444, EU $6^{\text {th }}$ Framework Food Quality and Safety Program. 
13. Ministero Agricultura (1999) Decreto Legislativo 30 Aprile 1998 n. 173 Decreto Ministero Agricoltura 8 September n. 350

14. European Union (1992) 2082/92 of 14 July 1992 on certificates of specific character for agricultural products and food status. Off J Eur Union pp: 9-14.

15. European Union (2006) 509/2006 of 20 March 2006 on agricultural products and foodstuffs as traditional specialties guaranteed. Off J Eur Union pp: 1-11.

16. European Union (2006) 510/2006 of 20 March 2006 on the protection of geographical indications and designations of origin for agricultural products and food stuffs. Off J Eur Union, pp: 12-25.

17. Sakali PC, Skalkos D (2016) Innovative agri-food supply chain network: Leading to traditional, "back to the future" foods. Int Journal of Business Science and Applied Management 11(2): 24-33.

18. Tomescu AM (2015) Consumer awareness of traditional food labeling as well as local products-A Local Perspective. Annals of Faculty of Economics, University of Oradea, Romania, 1(2): 562-572.
19. Porter ME (1990) The competitive advantage of nations. Free Press, New York, USA.

20. Rosin P, Spranca M, Krieger Z, Neuhaus R, Surillo D, et al. (2004) Preference for natural: Instrumental and ideational/moral motivations, and the contrast between foods and medicines. Appetite 43(2): 147-154.

21. Verbeke W, Frewer IL, Scholderer J, Brabander HF (2007) Why consumers behave as they do with respect to food safety and risk information. Anal Chim Acta 586(1-2): 2-7.

22. Olaimat AN, Shahbaz HM, Fatima N, Munir S, Holley RA (2020) Food safety during and after the era of COVID-19 pandemic. Frontiers in Microbiology.

23. Galanakis CM (2020) The food systems in the era of the coronavirus (COVID-19) pandemic crisis. Foods 9(4): 523.

24. Aday S, Aday MS (2020) Impact of COVID-19 on the food supply chain. Food Quality and Safety 4(4): 167-180.

For possible submissions Click below:

Submit Article 